Bangladesh J. Sci. Ind. Res. 43(1), 13-28, 2008

\title{
Investigations on the Redox Behavior and the Electrolysis Characteristics of Pd-20at.\%Ni Eectrode in 30wt.\% KOH Electrolyte
}

\author{
Mithun Sarker ${ }^{\mathrm{a}}$, M. Ashraful Islam Molla ${ }^{\mathrm{a}}$, Rafiqul Islama ${ }^{\mathrm{a}}$, Samina Ahmed \\ and A. K. M. Fazle Kibria ${ }^{*}$ \\ ${ }^{a}$ Department of Applied Chemistry and Chemical Technology, Dhaka University, \\ Dhaka-1000, ${ }^{b}$ Bangladesh Council of Scientific and Industrial Research (BCSIR), \\ Dhaka-1205 and 'Chemistry Division, Atomic Energy Centre, Ramna, Dhaka-1000, Bangladesh
}

\begin{abstract}
The redox behavior, surface reaction kinetics, stability, electrolysis characteristics and efficiency of a Pd-20 at. \%Ni electrode have been investigated in 30wt.\%KOH electrolyte at room temperature by using cyclic voltammetry. The electrode showed three couples of redox peaks in between the potential range -1.0 to $+0.65 \mathrm{~V}$. The origin of the peak couples were identified by cycling Pd and Ni electrodes independently in the same potential ranges. It was realized that the peak couples were originated from the transformations of $\mathrm{M}(0) \leftrightarrow \mathrm{M}$ (II) oxide, M(II) oxide $\leftrightarrow \mathrm{M}$ (III) oxide and M(III) oxide $\leftrightarrow$ M(IV) oxide, respectively. The term M represents the Pd-Ni alloy. The potentials of the peaks, potential differences of the peak couples and the peak currents found remarkably different than those of Pd and Ni electrodes. The redox reaction kinetics of the electrode showed combined surface reaction trends of Pd and $\mathrm{Ni}$ electrodes. The apparent stability of the electrode found good. The electrode showed equal and 4.2 times higher oxygen evolution current densities than those of $\mathrm{Ni}$ and Pd electrodes. Hydrogen evolution current density found 2.9 times lower than that of Pd electrode but $100 \%$ better than the Ni electrode at the potential range - 1.0 to $+0.65 \mathrm{~V}$. Almost $70 \%$ hydrogen evolution efficiency of Pd electrode was found at the potential range -1.0 to $-0.05 \mathrm{~V}$. On cycling the electrode at various potential ranges, it was found that the redox behavior resembled to that of Pd electrode at low potential ranges. The observed results indicated that Pd-20at.\%Ni electrode is a good electrode during electrolysis for oxygen evolution reaction and its electrolysis efficiency is far better than the Ni electrode.
\end{abstract}

Key words: Pd-20at. \%Ni electrode, Redox behavior, Hydrogen evolution, Oxygen evolution.

*Corresponding author 


\section{Introduction}

The general tendency of operating modern industrial electrolyzers at high current densities has stimulated research on materials with improved catalytic properties for both hydrogen and oxygen evolution reactions (Kreuter and Hofman, 1998). Hydrogen and oxygen evolution reactions are the basic cathodic and anodic reactions of an electrolyzer. Production of hydrogen and oxygen by water electrolysis is considered to be the most promising route because it is the only established technology for their production with high purity. However, hydrogen and oxygen production through this route is still expensive and thereby needs further research (Kaninski et al. 2006). Pure hydrogen and oxygen are essential to apply mainly in fuel cell to produce electricity, to run automotive vehicles and to generate metal hydride battery (Kreuter and Hofman 1998, Aki et al. 2006). Pure gases are essential to avoid poisoning of the cell electrodes.

Because of the high cost of noble metals $\mathrm{Pt}$ and $\mathrm{Au}$, cheaper non-noble transition metals like Fe (Dandapani and Bockris 1986), Ni (Huot and Brossard 1987, Kibria and Mridha 1996), Co (Kreysa and Haklansson 1986, Brossard 1991) and Raney nickel (Choquette et al. 1990) have been extensively using as electrode materials for water electrolysis. It has been reported that the stability of Fe is low than that of $\mathrm{Ni}$ and $\mathrm{Co}$ in acidic or alkaline medium. Moreover, high electrical energy is required to produce appreciable amounts of hydrogen and oxygen using these electrodes (Giz et al. 1990). So, there are ongoing search of alternative and effective electrode materials for electrolysis. By this time, researchers have tested the electrolysis performances of electrodes like $\mathrm{Co}-\mathrm{Cu}$ (Brossard and Marquis 1994), Ni-Cu (Kibria and Tarafdar 2002), Ni-Fe ( $\mathrm{Hu}$ and $\mathrm{Wu}$ 1993), Ni-Co (Chi et al. 2006), Pd-Ag (Vijh and Belanger, 1986), Pd-P (Podesta and Piatti 1997), etc. Nowadays, the surface behavior and the electrolysis efficiency of Pd and $\mathrm{Ni}$ electrodes are almost well known. Authors (Jaksic et al. 1993) have reported that Pd electrode is capable to evolve hydrogen at low driving forces. On the other hand, $\mathrm{Ni}$ requires high electrical driving force to produce hydrogen but comparatively low force to generate oxygen (Giz et al. 1990). In this sense, Pd-Ni alloy may be a good electro-catalyst for both the hydrogen and oxygen evolutions. This point of view insisted us to investigate on the electrochemical behavior of a Pd-Ni electrode. Study on Pd-Ni electrode is very limited. Recently, authors (Vracar et al. 1998) have investigated on the $\mathrm{M}(\mathrm{II}) \leftrightarrow \mathrm{M}(\mathrm{III})$ transformation characteristics of a Pd-Ni electrode having Pd mol\%63 and $\mathrm{Ni}$ mol\% 37 in a small potential range 0 to $0.65 \mathrm{~V}$ RHE.

On alloying, generally the crystallographic structure changes from those of its metal 
components. So, the redox potentials and peak currents of an alloy electrode remarkably vary than those of its single metal electrodes. Moreover, the redox behavior of a component of the alloy may predominate over that of other (Jaksic et al. 1998). In this situation, the surface property of the alloy electrode as well as its electrolysis property, efficiency and reaction kinetics may change remarkably from those of its components. Pd-Ni alloy consists of Pd and Ni. These two components establish a solid solution in all ranges of composition (Wicke et al. 1978, Vracar et al. 1998). In this situation, it is reasonable to assume some distinct redox behavior of Pd-Ni electrode than those of Pd and Ni electrodes. There may appear the predomination of Pd over $\mathrm{Ni}$ or vise versa. In this context, the present investigations attempt to find out the differences in electrochemical redox behavior, hydrogen and oxygen evolution characteristics and efficiencies, redox kinetics, etc. of a Pd-Ni alloy than those of its components $\mathrm{Pd}$ and $\mathrm{Ni}$ in alkaline medium. It was interest to see if on alloying the electrode confer further electrocatalytic activity.

\section{Materials and Methods}

Palladium and nickel of purity 99.9 wt.\% was purchased from Tanaka Kikinzoku Kogyo, Japan, and was used to prepare PdNi alloy. Pd-20at.\%Ni alloy was prepared by non-consumable arc melting in an argon atmosphere. The alloy button was then annealed for $5 \mathrm{~h}$ at $973 \mathrm{~K}$ in vacuum. It was then rolled into a sheet of $1 \mathrm{~mm}$ thickness and cut into square size to prepare the working electrode. The square sized electrode was then spot welded with a nickel wire connector. The lower part of the connecting wire was then insulated by a pyrex glass pipe and epoxy resin. The geometric area of the electrode was $2.02 \mathrm{~cm}^{2}$. A nickel sheet of area $9.25 \mathrm{~cm}^{2}$ was used as counter electrode. To remove any oxides present on the surface of the electrodes, these were chemically etched with 2:2:1 $\mathrm{H}_{2} \mathrm{SO}_{4}: \mathrm{HNO}_{3}: \mathrm{H}_{2} \mathrm{O}$ solution. The electrode surfaces were then polished with $0.3 \mathrm{~mm}$ alumina paste and subsequently rinsed with deionized water. The used electrolyte was $30 \mathrm{wt} \% \mathrm{KOH}$ solution. It was prepared from reagent grade $\mathrm{KOH}$ pellets.

A three-electrode cylindrical electrochemical cell indigenously designed and developed in the electrochemistry laboratory, AEC, was used for the experimental measurements. The indigenously prepared working electrode, counter electrode and the $\mathrm{Hg} / \mathrm{HgO} . \mathrm{OH}^{-}$reference electrode were immersed in $100 \mathrm{ml}$ electrolyte in triangular way. The luggin capillary end of the reference electrode was placed approximately 2 $\mathrm{mm}$ apart from the surface of the working electrode in order to minimize the internal resistance (IR). The electrolyte was freed from dissolved oxygen by bubbling $\mathrm{N}_{2}$ gas for half an hour. Cyclic voltammetric measurements of the electrode were carried out by EG and G PARC Model 362 potentiostat/ 
Galvanostat and current-potential responses were drawn by EG and G PARC Model RE $0089 \mathrm{X}-\mathrm{Y}$ recorder. The electrode was activated initially by maintaining a cathodic potential - 1.0 V for half an hour. The redox transformations and the hydrogen and oxygen evolution characteristics of the alloy materials were investigated in between the potential range -1.0 to $+0.65 \mathrm{~V}$ by applying potential sweep rate $100 \mathrm{mV} / \mathrm{s}$. In order to understand the surface redox reaction kinetics, potential sweep rates 20 to $200 \mathrm{mV} / \mathrm{s}$ were used. The experiments were carried out at room temperature.

\section{Results and Discussion}

Figure 1 shows the cyclic voltammogram appeared for the Pd-20 at. \% Ni electrode in

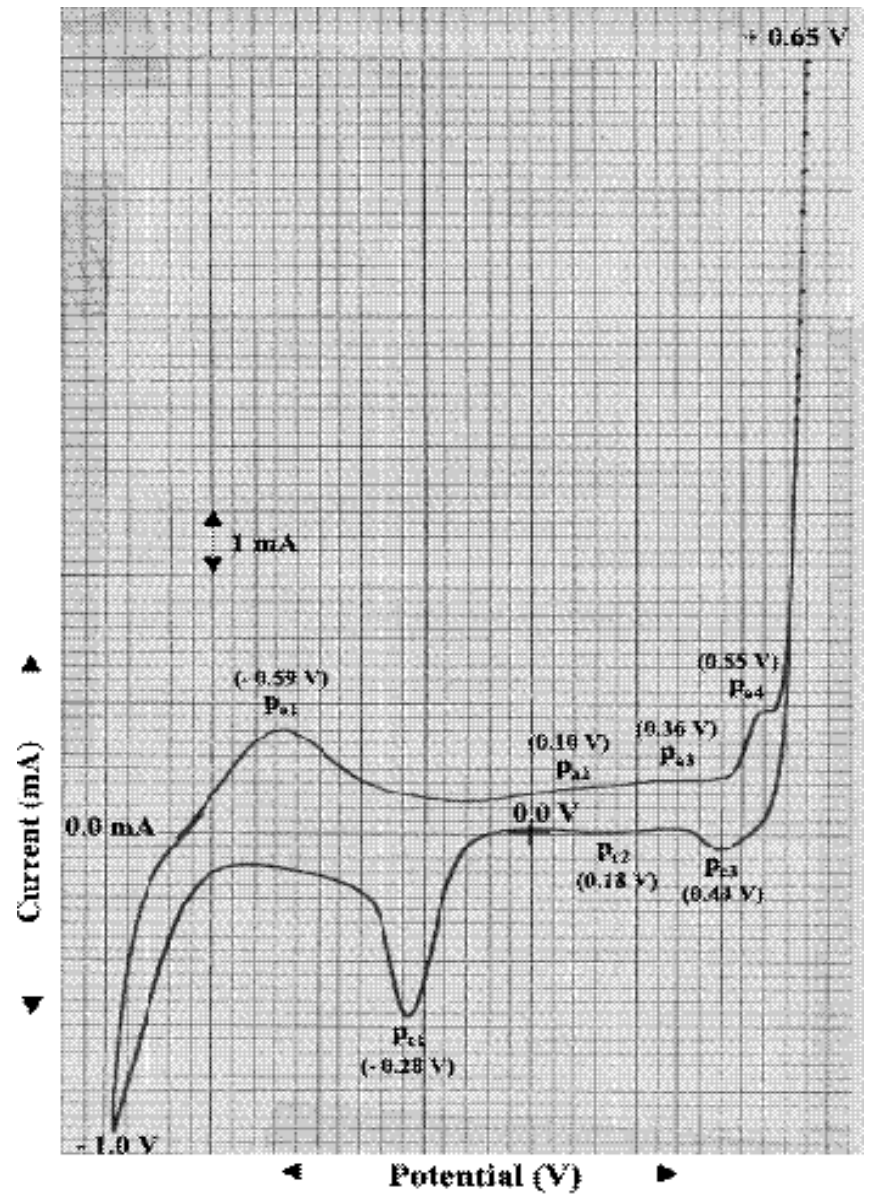

Fig. 1. Cyclic voltammogram of Pd-20at.\%Ni electrode in 30wt.\% $\mathrm{KOH}$ electrolyte in between the potential range $-1.0 \mathrm{~V}$ to $+0.65 \mathrm{~V}$ at scan rate $100 \mathrm{mV} / \mathrm{s}$. 
30wt.\% KOH electrolyte in between the potential range $-1.0 \mathrm{~V}$ to $+0.65 \mathrm{~V}$ at $300 \mathrm{~K}$ at the scan rate of $100 \mathrm{mV} / \mathrm{s}$. It can be seen that four anodic peaks represented as pa1, pa2, ра3 and pa4 and three cathodic peaks designed as pc1, pc2 and pc3 are appeared in the voltammogram. The anodic peak potentials are $0.59 \mathrm{~V}, 0.10 \mathrm{~V}, 0.36 \mathrm{~V}$ and $0.55 \mathrm{~V}$, and the cathodic peak potentials are $-0.28 \mathrm{~V}, 0.18 \mathrm{~V}$ and $0.44 \mathrm{~V}$, respectively. It seems that paz and pc1, pa3 and pc2, and pa4 and pc3 are couple of redox peaks. The peak pa1 seems appeared due to the desorption of diffusional hydrogen absorped in the interstitial position of $\mathrm{Pd}-\mathrm{Ni}$ lattice. Pd present in the Pd-Ni electrode is mainly responsible for this hydrogen desorption because it has capability to absorp and desorp enormous amount of hydrogen (Kibria and Sakamoto 1997). Hydrogen absorption-desorption nature of $\mathrm{Ni}$ is different from those of Pd. It has poor absorption and desorption capability (Lewis 1967). It may be seen that oxygen evolution current is maximum at the set potential $0.65 \mathrm{~V}$. Current for oxygen evolution sharply decreased with decreasing the potential and seems reached to the minimum value at about the potential $0.57 \mathrm{~V}$.

The prerequisite condition for the oxygen evolution over an electrode is the formation of M(IV) oxide. Oxygen evolution occurs due to its reduction and decomposition to $\mathrm{M}(\mathrm{III})$ oxide and oxygen by following different surface reaction steps (Conway et al. 1987). For an electrode of $M(0)$ state, it requires three consecutive transformation steps of the surface to reach M(IV) oxide state. The transformations can be represented as $\mathrm{M}(0) \rightarrow \mathrm{M}(\mathrm{II}), \mathrm{M}(\mathrm{II}) \rightarrow \mathrm{M}$ (III) and M(III) $\rightarrow \mathrm{M}(\mathrm{IV})$ oxides, respectively. In the present case, transformation of $\mathrm{M}$ (III) $\rightarrow \mathrm{M}(\mathrm{IV})$ oxide began at about the potential $0.57 \mathrm{~V}$. Here $\mathrm{M}$ represents $\mathrm{Pd}-\mathrm{Ni}$ alloy. Its preceding peak pa4 seems the major peak or only the peak for the transformation of $\mathrm{M}(\mathrm{II}) \rightarrow$ M(III) oxide. Peak pa3 may be a peak for the like transformation of a component of the alloy. The peak paz probably originated from the transformation of $\mathrm{M}(0) \rightarrow \mathrm{M}$ (II) oxide. The facts regarding the origin of the peaks are not clear at this moment. However, the peaks were identified after doing some additional works and these were discussed latter.

From the Fig. 1, it can be seen that adsorption of hydrogen on the surface of the electrode began at about the potential $-0.67 \mathrm{~V}$. Maximum current for hydrogen evolution appeared at the set potential - $1.0 \mathrm{~V}$. Hydrogen evolution occurred probably by following the successive necessary steps involving hydrogen adsorption over the electrode surface and desorption of adsorped hydrogen (Jaksic et al. 1993). Form the voltammogram, it is clear that peaks pa1, pa4, pc1 and pc3 showed remarkable currents whereas those of other three peaks are very small.

In order to find out the facts, how the electrochemical behavior of Pd-20at.\%Ni alloy 
is different if any from those of its components, cyclic voltammetric studies of Pd and Ni electrodes were carried out independently by adopting the same experimental conditions as followed for Pd-20at.\%Ni electrode. Figure 2 shows the cyclic voltammogram observed for the pure Pd electrode. It can be seen that three anodic peaks designed as pa1, pa2 and pa3, and two cathodic peaks pc1 and pc2 are appeared in the voltammogram. The peak potentials are $-0.41 \mathrm{~V}, 0.34 \mathrm{~V}, 0.51 \mathrm{~V}$, $0.27 \mathrm{~V}$ and $0.25 \mathrm{~V}$, respectively. The shape of the voltammogram is analogous to those observed by the authors (Jaksic et al. 1993) for the Pd electrode in $0.1 \mathrm{M} \mathrm{KOH}$ at the scan rate $200 \mathrm{mV} / \mathrm{s}$. It seems that peaks pa2 and pc1 and peaks ра3 and pc2 are couple of redox peaks. These are appeared due to the transformations of $\operatorname{Pd}(0) \leftrightarrow P d(I I)$ oxide and $\mathrm{Pd}(\mathrm{II})$ oxide $\leftrightarrow$ Pd(III) oxide, respectively. Transformation of $\mathrm{Pd}(\mathrm{III}) \rightarrow \mathrm{Pd}(\mathrm{IV})$ oxide began at about the potential $0.58 \mathrm{~V}$. Oxygen evolution occurred due to its reduction and decomposition to Pd(III) oxide. The rest anodic peak pa1 appeared due to the desorption of diffusional hydrogen absorped in the Pd lattice (Jaksic et al. 1993). Adsorption of hydrogen on the electrode surface began from about the potential - 0.58 V. Maximum hydrogen evolution occurred from the set potential $-1.0 \mathrm{~V}$. Peaks $\mathrm{p}_{\mathrm{c} 1}$ and $\mathrm{pa1}$ corresponded to $\mathrm{Pd}(\mathrm{II})$ oxide $\rightarrow \operatorname{Pd}(0)$ transformation and desorption of diffusional hydrogen showed remarkable currents whereas those of other peaks are small.

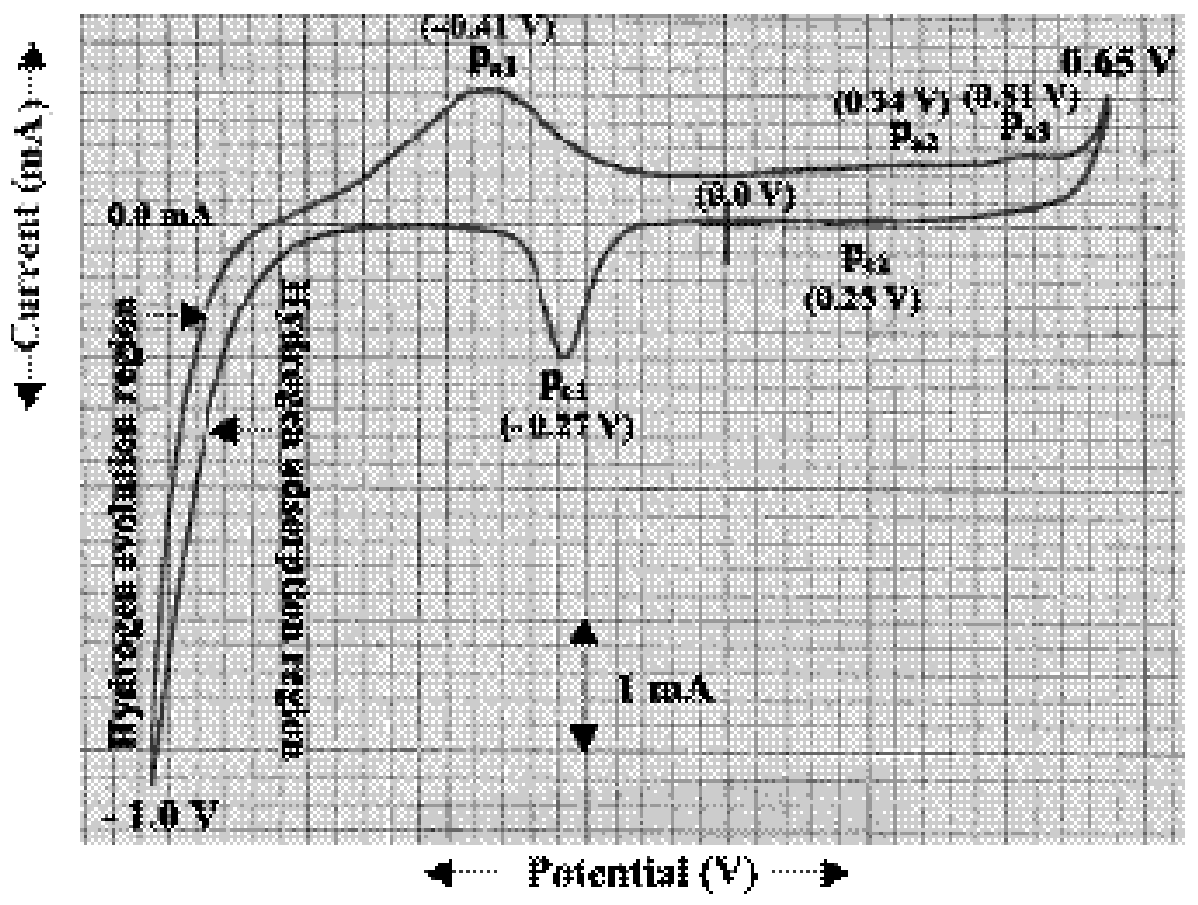

Fig. 2. Cyclic voltammogram of Pd electrode in 30wt.\% $\% \mathrm{KH}$ electrolyte in between the potential range $-1.0 \mathrm{~V}$ to $+0.65 \mathrm{~V}$ at scan rate $100 \mathrm{mV} / \mathrm{s}$. 
Figure 3 shows the cyclic voltammogram appeared for the pure Ni electrode. It can be seen that a couple of redox peaks designed as $\mathrm{pa} 1$ and $\mathrm{pc} 1$ are appeared in the voltammogram. The peak potentials are $0.48 \mathrm{~V}$ and $0.40 \mathrm{~V}$, respectively. The shape of the voltammogram is analogous to that observed earlier and the peak potential values coincided with the reported values (Brossard 1991, Kibria and Mridha 1996). The couple of redox peaks appeared due to the transformation of $\mathrm{Ni}$ (II) oxide $\rightarrow \mathrm{Ni}$ (III) oxide. Transformation of $\mathrm{Ni}(\mathrm{III}) \rightarrow \mathrm{Ni}(\mathrm{IV})$ oxide began at about the potential $0.57 \mathrm{~V}$. Oxygen evolution occurred from the set potential + $0.65 \mathrm{~V}$ due to the reduction and decomposition of $\mathrm{Ni}(\mathrm{IV}) \rightarrow \mathrm{Ni}(\mathrm{III})$ oxide (Brossard 1991, Conway et al. 1987). Current for oxygen evolution decreased as usually with decreasing the potential. The redox couple showed remarkable currents. It can be seen that the set negative potential - $1.0 \mathrm{~V}$ was not enough to adsorp hydrogen and to commence hydrogen evolution. The observed result coincided with that reported by the authors (Giz et al. 1990). The finding again confirmed that high potential is required to achieve hydrogen evolution over $\mathrm{Ni}$ elec-

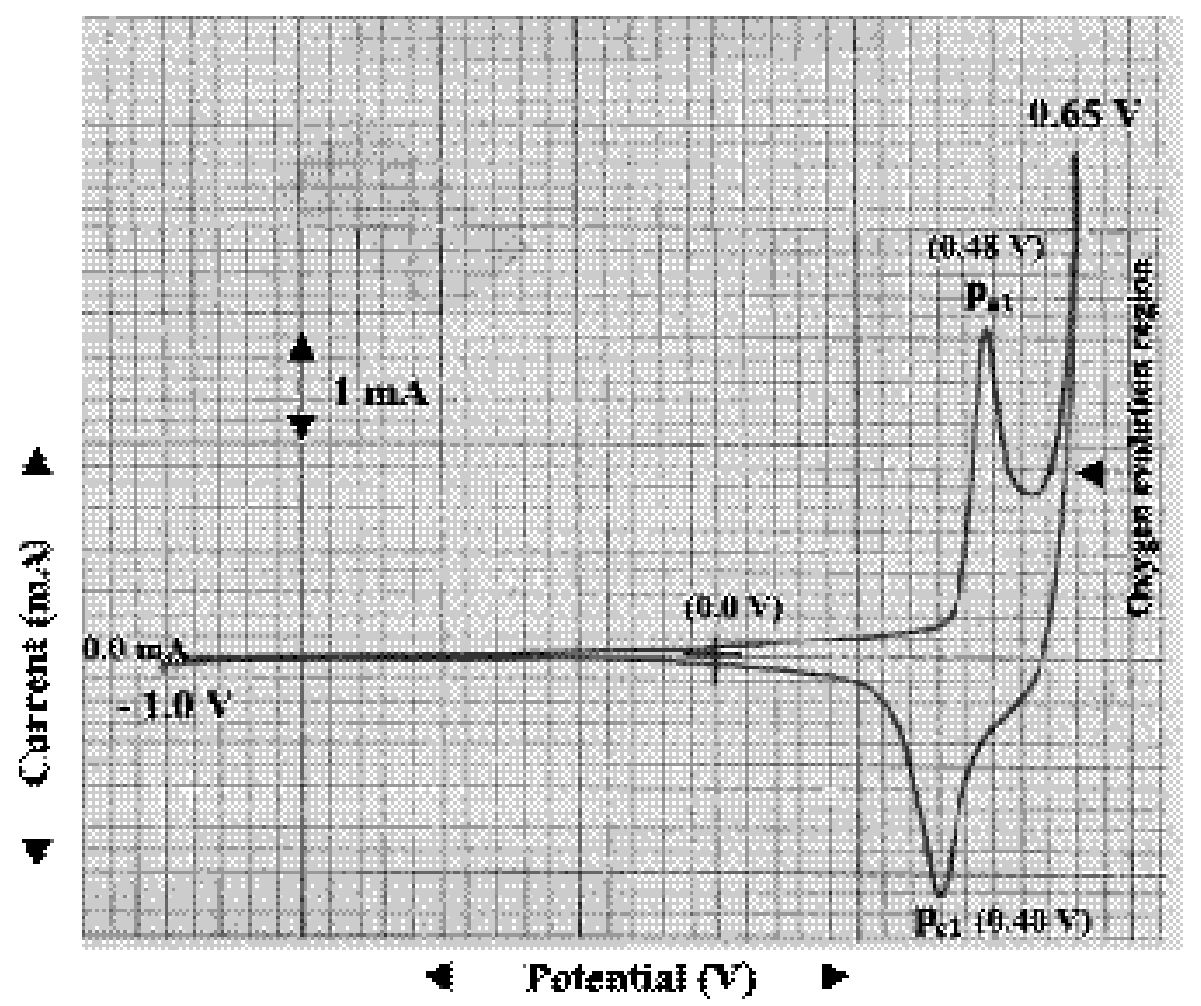

Fig. 3. Cyclic voltammogram of Ni electrode in $30 \mathrm{wt} . \% \mathrm{KOH}$ electrolyte in between the potential range $-1.0 \mathrm{~V}$ to $+0.65 \mathrm{~V}$ at scan rate $100 \mathrm{mV} / \mathrm{s}$. 
trode than the Pd electrode. No remarkable peaks for $\mathrm{Ni}(0) \leftrightarrow \mathrm{Ni}$ (II) oxide transformations were observed. In an earlier study (Kibria et al. 1995), the peaks for these transformations were found at $-0.62 \mathrm{~V}$ and $0.94 \mathrm{~V}$ after cycling a $\mathrm{Ni}$ electrode in between the potential $-1.1 \mathrm{~V}$ to $-0.3 \mathrm{~V}$.

Comparing the redox behavior of Pd20at\%Ni electrode (Fig. 1) with that of pure Pd and Ni electrodes (Figs. 2 and 3), it can be said that transformation of M(III) $\rightarrow \mathrm{M}(\mathrm{IV})$ oxide began from about the same potential $0.57 \mathrm{~V}$ as those appeared for both Pd(III) $\rightarrow$ $\mathrm{Pd}(\mathrm{IV})$ and $\mathrm{Ni}(\mathrm{III}) \rightarrow \mathrm{Ni}(\mathrm{IV})$ oxides. Commencement of adsorption of hydrogen over the Pd-20at \%Ni electrode surface and desorption of diffusional hydrogen from its lattice interstices occurred at about $0.10 \mathrm{~V}$ and $0.18 \mathrm{~V}$ negative potentials than those of Pd electrode. Peak couples pa2 and pc1, and ра3 and pc2 of Pd-20at\%Ni electrode seem resembled to those of Pd electrode. On the other hand, peak couple pa4 and pc3 of Pd$20 \mathrm{at} \% \mathrm{Ni}$ electrode seem resembled to the peak couple pa1 and pc1 of Ni electrode. M(0) $\rightarrow \mathrm{M}$ (II) transformation occurred about 0.24 $\mathrm{V}$ negative potential than that of $\mathrm{Pd}(0) \rightarrow$ $\operatorname{Pd}(\mathrm{II})$ transformation but that for reduction, i.e., $\mathrm{Pd}(0) \leftarrow \mathrm{Pd}(\mathrm{II})$ transformation remained almost constant at $-0.27 \mathrm{~V}$. So, the peak couple comes $0.24 \mathrm{~V}$ closer. Palladium related M(II) oxide $\leftrightarrow$ M(III) oxide transformations occurred at about $0.15 \mathrm{~V}$ and $0.07 \mathrm{~V}$ negative potentials than those of $\mathrm{Pd}(\mathrm{II})$ oxide $\leftrightarrow$ Pd(III) oxide transformations. The peak cou- ple comes $0.08 \mathrm{~V}$ closer. It indicates that due to addition of Ni with Pd, palladium related $\mathrm{M}(0) \rightarrow \mathrm{M}(\mathrm{II})$ oxide and M(II) oxide $\leftrightarrow$ M(III) oxide transformations became faster than those of Pd electrode. Nickel relevant M(II) oxide $\leftrightarrow$ M(III) oxide transformations occurred over the Pd(III) oxide layer at about $0.07 \mathrm{~V}$ and $0.04 \mathrm{~V}$ positive potentials than those of $\mathrm{Ni}(\mathrm{II})$ oxide $\leftrightarrow \mathrm{Ni}$ (III) oxide transformations. The peak couple moves $0.03 \mathrm{~V}$ far. It means that in Pd-20at.\%Ni electrode, Ni related M(II) oxide $\leftrightarrow$ M(III) oxide transformations became slower than those of $\mathrm{Ni}$ electrode. On the other hand, M(II) $\rightarrow$ M(III) oxide transformation is $0.04 \mathrm{~V}$ higher than the $\mathrm{Pd}(\mathrm{II}) \rightarrow \mathrm{Pd}(\mathrm{III})$ oxide transformation. It informs that both the Pd and Ni showed their independent behavior at this stage. The peaks $\mathrm{p}_{\mathrm{a} 3}$ and $\mathrm{p}_{\mathrm{a} 4}$ are originated from the transformation of M(II) $\rightarrow$ M(III) oxides and their potentials are also different from those of their single metal electrodes. Addition of $\mathrm{Ni}$ with Pd changed the redox potential of $\mathrm{Ni}$ and Pd related peaks remarkably.

From the Fig. 1, it can be seen that current densities for the desorption of diffusional hydrogen, $\mathrm{M}(\mathrm{II}) \rightarrow \mathrm{M}(\mathrm{III})$ oxide transformation, $\mathrm{M}(0) \leftarrow \mathrm{M}(\mathrm{II})$ oxide transformation, hydrogen and oxygen evolutions are about $0.7,0.5,1.4,2.5$ and $5.6 \mathrm{~mA} / \mathrm{cm}^{2}$, respectively. In case of Ni electrode (Fig. 2), current densities for the $\mathrm{Ni}$ (II) oxide $\leftrightarrow \mathrm{Ni}$ (III) oxide transformations and oxygen evolution are about 3.1, 2.4 and $5.5 \mathrm{~mA} / \mathrm{cm}^{2}$. The area of the Ni electrode is $0.88 \mathrm{~cm}^{2}$. For Pd electrode 
(Fig. 3), current densities for the desorption of diffusional hydrogen, $\operatorname{Pd}(0) \leftarrow \operatorname{Pd}(\mathrm{II})$ oxide transformation, hydrogen and oxygen evolutions are about 1.3, 1.6, 7.2 and 1.3 $\mathrm{mA} / \mathrm{cm}^{2}$. The area of the Pd electrode is 0.62 $\mathrm{cm}^{2}$. From the above findings, it is clear that Pd-20at.\%Ni electrode showed 50\% lower current density than that found for Pd electrode for the desorption of diffusional hydrogen. On the other hand, M(II) $\rightarrow$ M(III) oxide transformation showed more than 6 times lower current density than that of $\mathrm{Ni}(\mathrm{II}) \rightarrow \mathrm{Ni}(\mathrm{III})$ transformation. Again, $\mathrm{M}(0)$ $\leftarrow$ M(II) transformation showed 0.9 times current density than that of $\operatorname{Pd}(0) \leftarrow \operatorname{Pd}($ II) transformation. It indicates the formation of lower amount of $\mathrm{Pd}(\mathrm{II})$ oxide layer on the surface of the Pd-Ni electrode than the Pd electrode. It is reasonable because the amount of Pd in Pd-20.at\%Ni electrode is lower than that of Pd electrode. Hydrogen evolution current density is 2.9 times lower than that of Pd electrode but oxygen evolution current density is equal and 4.2 times higher than those of $\mathrm{Ni}$ and Pd electrodes, respectively. It informs that M(II) oxide film grown over the electrode surface significantly transformed to M(III) oxide and then $\mathrm{M}(\mathrm{III}) \rightarrow \mathrm{M}(\mathrm{IV})$ oxide (Kibria and Tarafdar 2002).

Fig. 4 shows the cyclic voltammograms appeared for Pd-at.20\% Ni electrode at the scan rates of 20, 50, 100 and $200 \mathrm{mV} / \mathrm{sec}$ in between the potential range -1.0 to $+0.65 \mathrm{~V}$. It can be seen that the redox behaviors pre- served the same trend with the variation of scan rates. Peak currents gradually increased, anodic peaks pa1 and pa4 gradually shifted to the positive potential direction and the cathodic peak pc1 significantly shifted to the negative potential direction. Analogous redox behaviors and shiftment of peaks relevant to pa1, pa4 and pc1 were also observed on Pd and Ni electrode surfaces at different scan rates. An additional information, i.e., a shoulder of new cathodic peak appeared at about $-0.70 \mathrm{~V}$ at the scan rate $200 \mathrm{mV} / \mathrm{s}$. This cathodic peak may appear for the reduction of $\mathrm{Ni}(\mathrm{II})$ oxide to $\mathrm{Ni}(0)$. Figure 5 shows the peak currents $\left(\mathrm{I}_{\mathrm{pa}, \mathrm{c}}\right)$ against square root of scan rates $\left(\mathrm{V}^{1 / 2}\right)$ relationships of the significant transformation peaks $\mathrm{Pd}(0) \leftarrow \mathrm{Pd}(\mathrm{II})$ oxide, $\mathrm{Ni}(\mathrm{II}) \rightarrow \mathrm{Ni}$ (III) oxide, $\mathrm{M}(0) \leftarrow \mathrm{M}$ (II) oxide and $\mathrm{M}(\mathrm{II}) \rightarrow \mathrm{M}(\mathrm{III})$ oxide of $\mathrm{Pd}, \mathrm{Ni}$ and Pd-20at.\%Ni electrodes. It can be seen that $I_{\mathrm{pa}, \mathrm{c}}$ values show linear dependences with $\mathrm{V}^{1 / 2}$. But none of them passed through the origin. It indicates that above transformations are not purely diffusion-controlled processes. Vracar et al. (1998) have also observed the similar trend for $\mathrm{M}(\mathrm{II}) \rightarrow$ $\mathrm{M}(\mathrm{III})$ oxide transformation process of $\mathrm{Pd}$ mol\%63-Ni mol\%37 electrode. Addition of Ni with Pd is not changing the surface redox reaction kinetics. The surface reaction behavior of Pd-20at.\%Ni electrode showed like and combined behaviors of $\mathrm{Pd}$ and $\mathrm{Ni}$ electrodes.

Fig. 6 shows the cyclic voltammograms obtained for Pd-20at \% Ni electrode at 2, 5, 


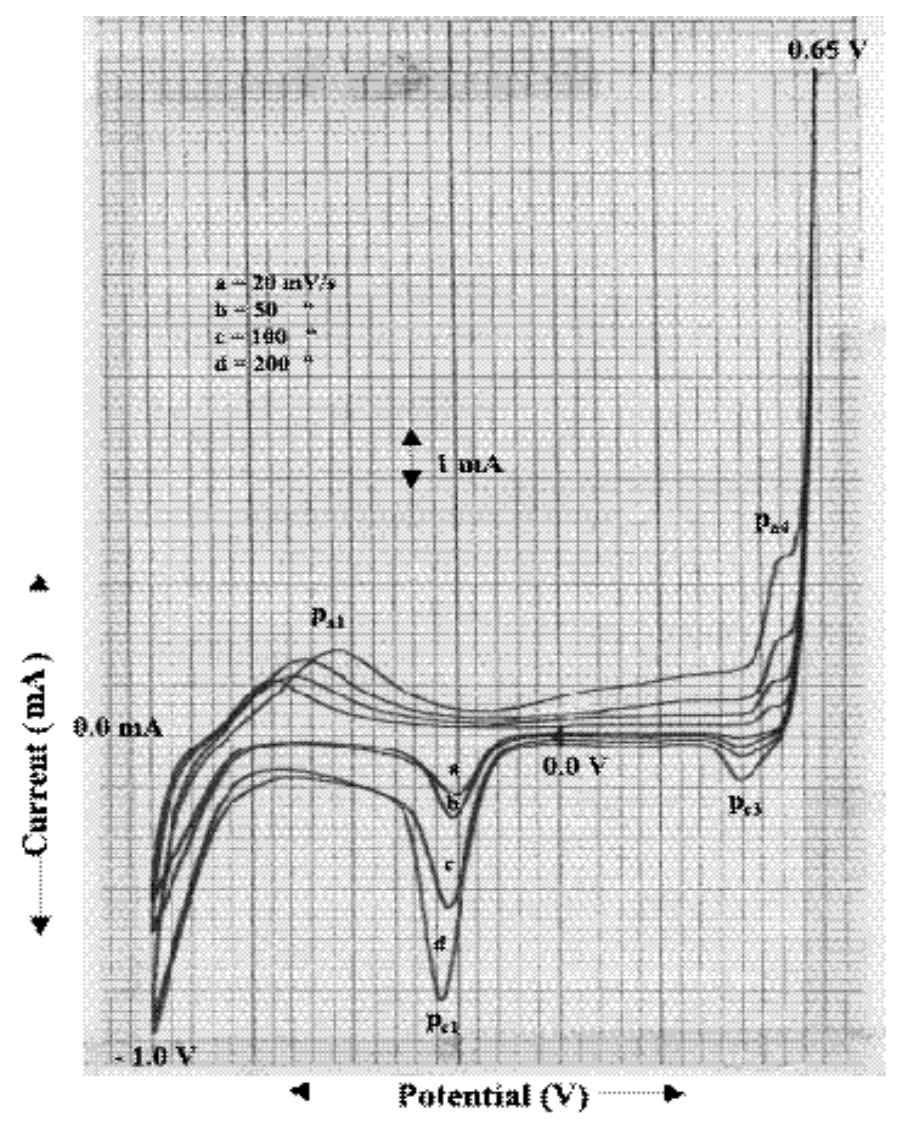

Fig. 4. Cyclic voltammograms of Pd-20at.\%Ni electrode in 30wt.\%KOH electrolyte in between the potential range $-1.0 \mathrm{~V}$ to $+0.65 \mathrm{~V}$ at different scan rates.

15, 25, 40 and 60 minutes at scan rate of 100 $\mathrm{mV} / \mathrm{sec}$ between the potential range -1.0 to $+0.61 \mathrm{~V}$. The observed behaviors are analogous to that appeared during cyclic the electrode in the potential range -1.0 to $+0.65 \mathrm{~V}$ as shown in Fig. 1. It can be seen that current for desoption of diffusional hydrogen and Pd related $\mathrm{M}(0) \rightarrow \mathrm{M}(\mathrm{II})$ oxide and $\mathrm{M}(\mathrm{II})$ oxide $\leftrightarrow \mathrm{M}$ (III) oxide transformations remained almost constant. Currents for Pd related $\mathrm{M}(0) \leftarrow \mathrm{M}$ (II) oxide and Ni related M(II) oxide $\leftrightarrow$ M(III) oxide transformations gradu- ally increased with increasing time. The behaviors are analogous to the combined time dependent behaviors of Pd and Ni electrodes. A shoulder of cathodic peak suspected for $\mathrm{Ni}(\mathrm{II}) \rightarrow \mathrm{Ni}(0)$ transformation as observed during scanning the electrode at $200 \mathrm{mV} / \mathrm{s}$ (Fig. 4) also appeared at about the same potential - $0.70 \mathrm{~V}$ after prolonged scanning. It may be taken as an information that hydrogen adsorption appeared over the electrode surface whose a fraction was covered by $\mathrm{Ni}(\mathrm{II})$ oxide. It may hinder in getting better 


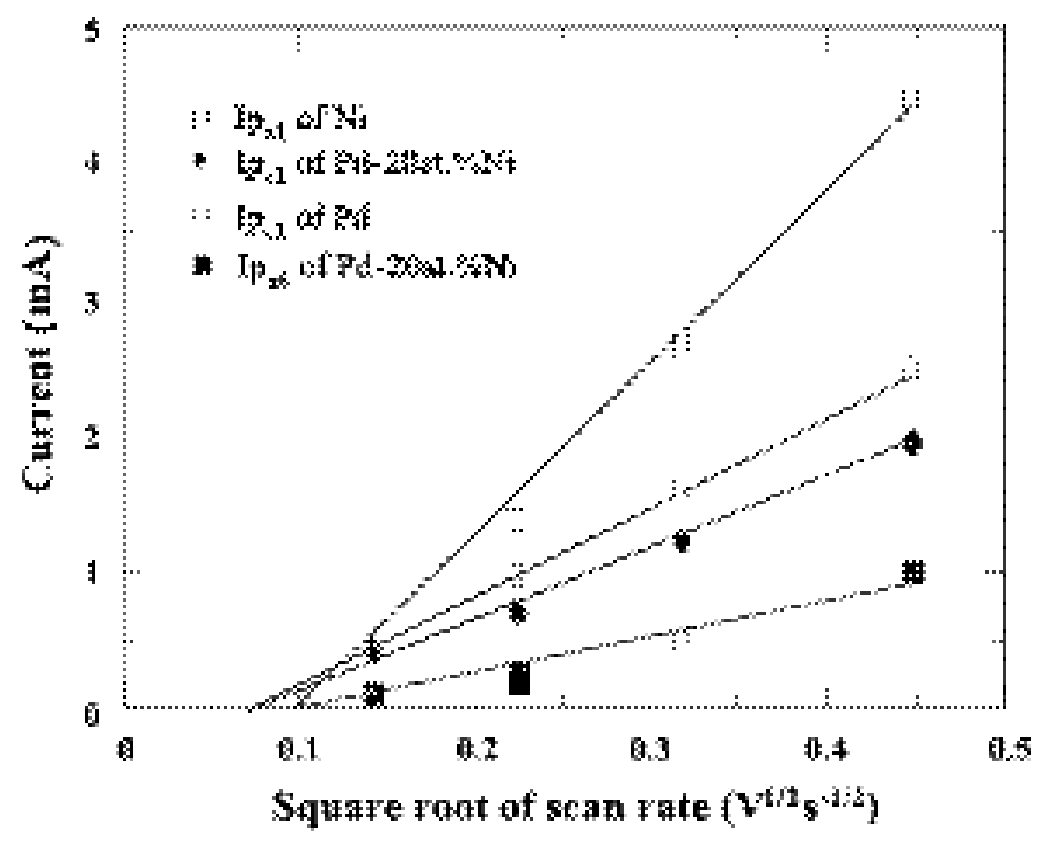

Fig. 5. Dependence of peak currents with the square root of scan rates of Pd, Ni and Pd-20at.\% Ni electrodes in 30wt.\% KOH electrolyte.

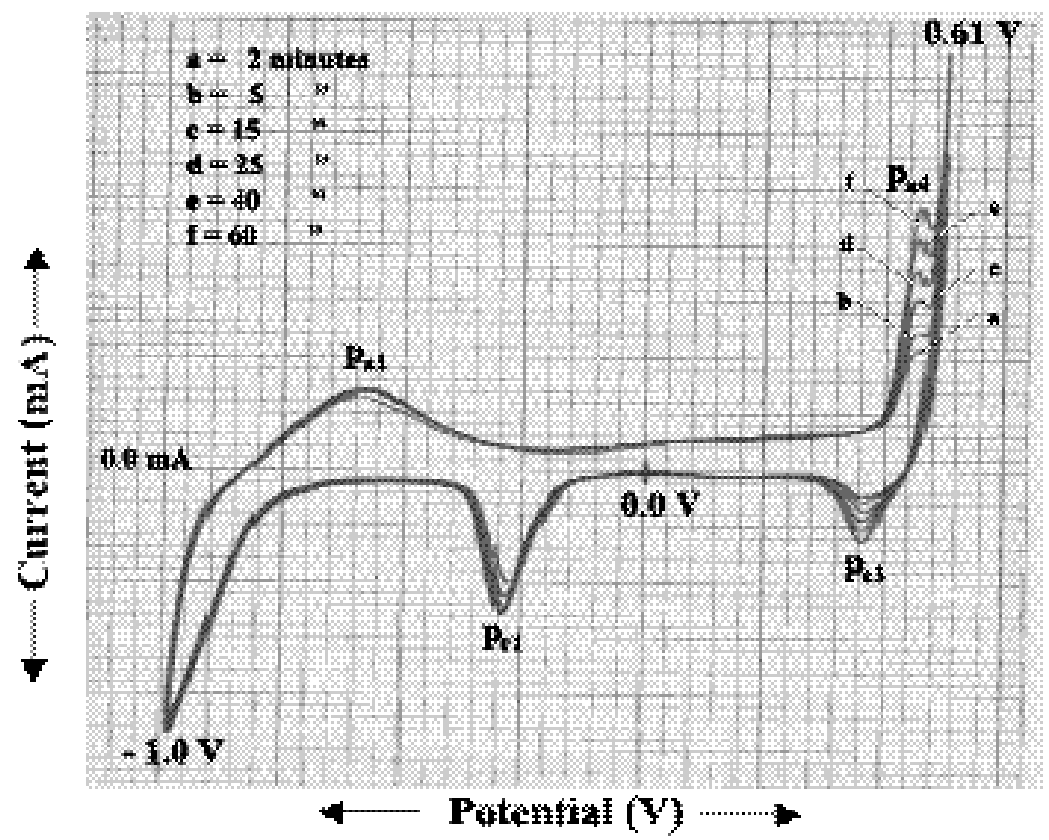

Fig. 6. Cyclic voltammograms of Pd-20at.\%Ni electrode at different time in $30 \mathrm{wt} \% \mathrm{KOH}$ electrolyte in between the potential range $-1.0 \mathrm{~V}$ to $+0.61 \mathrm{~V}$. 
efficiency of this electrode for hydrogen evolution at the experimental potential range. Increase in Ni related current density for $\mathrm{M}(\mathrm{II}) \rightarrow \mathrm{M}$ (III) oxide transformation after 15 minutes is $1.1 \mathrm{~mA} / \mathrm{cm}^{2}$ which is 2.0 times higher than the initial current density and the value reached to 4.0 times after 60 minutes. It indicates that the thickness of $\mathrm{Ni}$ (III) oxide film over the electrode surface gradually increased. It means that oxygen evolution capacity of the electrode gradually increased with time. Current for Pd related $\mathrm{M}(0) \leftarrow \mathrm{M}(\mathrm{II})$ oxide transformation initially increased with time. After 15 minutes current showed a constant value. It means that formation of Pd(II) oxide layer over the surface remained constant. Both the hydrogen evolution current and that for desorption of diffusional hydrogen also remained constant with time. It indicates that the apparent stability of Pd-Ni electrode is good.

In order to understand the effect of variation of potential range on the redox behavior of Pd-20at.\%Ni electrode, studies were carried out by fixing negative potential at $-1.0 \mathrm{~V}$ and varying the positive potential from $0.65 \mathrm{~V}$ towards negative direction at a scale of 0.05 $\mathrm{V}$ at the scan rate $100 \mathrm{mV} / \mathrm{sec}$. The cyclic voltammograms observed at various potential ranges are shown in Figs. $7 \mathrm{a}$ and $7 \mathrm{~b}$. From the Fig. 7a, it can be seen that currents for oxygen evolution and M(II) oxide $\rightarrow$ M(III) oxide transformations gradually decreased with decreasing the potential range. Transformations of these oxides dis- appeared at above the potential $0.50 \mathrm{~V}$. Peak current for $\mathrm{M}(0) \rightarrow \mathrm{M}(\mathrm{II})$ oxide transformation gradually decreased and the peak potential gradually shifted to the positive potential direction. It occurred due to the gradual decrease in formation of Pd related $\mathrm{M}(0) \rightarrow$ $\mathrm{M}(\mathrm{II})$ oxide. It means that the surface of the electrode gradually freed from M(II) oxide and fraction of $\mathrm{M}(0)$ surface gradually increased. Peak potential for the desorption of diffusional hydrogen peak gradually shifted to the negative potential direction. Current for hydrogen evolution and concurrently that of desorption of diffusional hydrogen gradually increased with decreasing the potential range. It indicates that with increasing the $\mathrm{M}(0)$ surface both the hydrogen adsorption on the electrode surface and absorption of hydrogen in the lattice of the electrode gradually increased. It supports that for hydrogen evolution, $\mathrm{M}(0)$ surface is essential because atomic hydrogen adsorps only on the $\mathrm{M}(0)$ surface of an electrode. However, from Fig. 7b, it is clear that increase in currents continued up to the potential range - 1.0 to $-0.05 \mathrm{~V}$. At this potential range, hydrogen evolution current is $4.9 \mathrm{~mA} / \mathrm{cm}^{2}$. This current value is 2.0 times higher than that of the same electrode but only 0.7 times than that of pure Pd electrode found during cycling in between the potential -1.0 to $+0.65 \mathrm{~V}$. Then current decreased with further decrease in potential range. In case of pure Pd electrode, currents for hydrogen evolution and desoption of diffusional hydrogen also increased with 


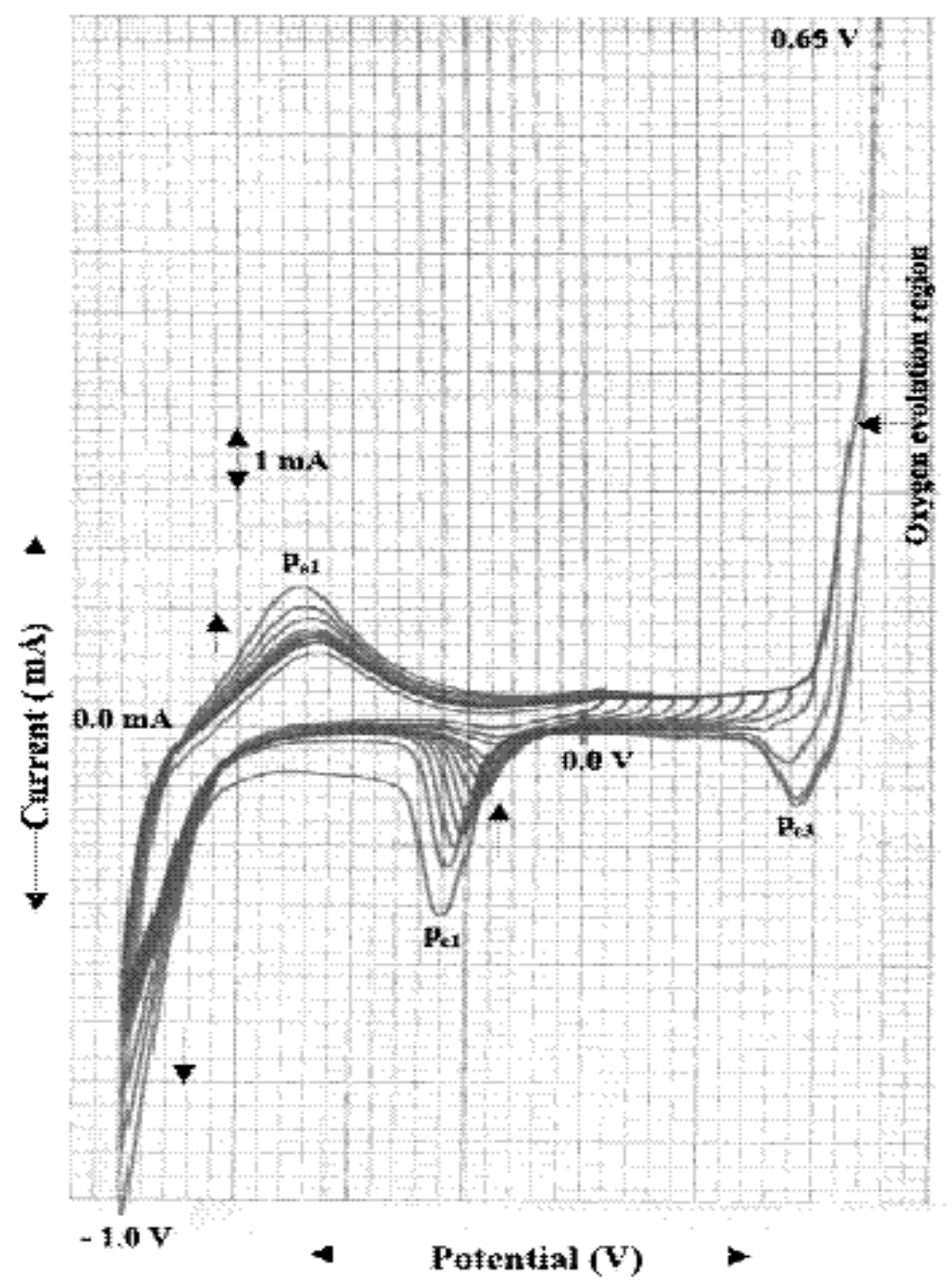

Fig. 7a. Cyclic voltammograms of Pd-20at.\%Ni electrode in 30wt.\% KOH electrolyte in between the potential ranges $-1.0 \mathrm{~V}$ and $+0.65 \mathrm{~V}$ to $0.05 \mathrm{~V}$.

decreasing the potential range (Jaksic et al. 1993). Current for the desoption of diffusional hydrogen at this potential range is 1.3 $\mathrm{mA} / \mathrm{cm}^{2}$ and it is $86 \%$ higher than that observed at the potential range -1.0 to +0.65 $\mathrm{V}$. This value equal to that appeared for pure Pd electrode at the same potential range but lower than that appeared at the potential range - 1.0 to $-0.05 \mathrm{~V}$. It indicates that hydrogen absorption in the Pd-20at.\%Ni lat tice is lower than that of pure Pd as $100 \%$ hydrogen easily desorps from the Pd lattice. This may occur due to the decrease in lattice size when Pd alloyed with Ni, i.e. Pd-Ni is lattice-contracted alloy (Wicke et al. 1978, Lewis 1967). The volume of its octahedral 


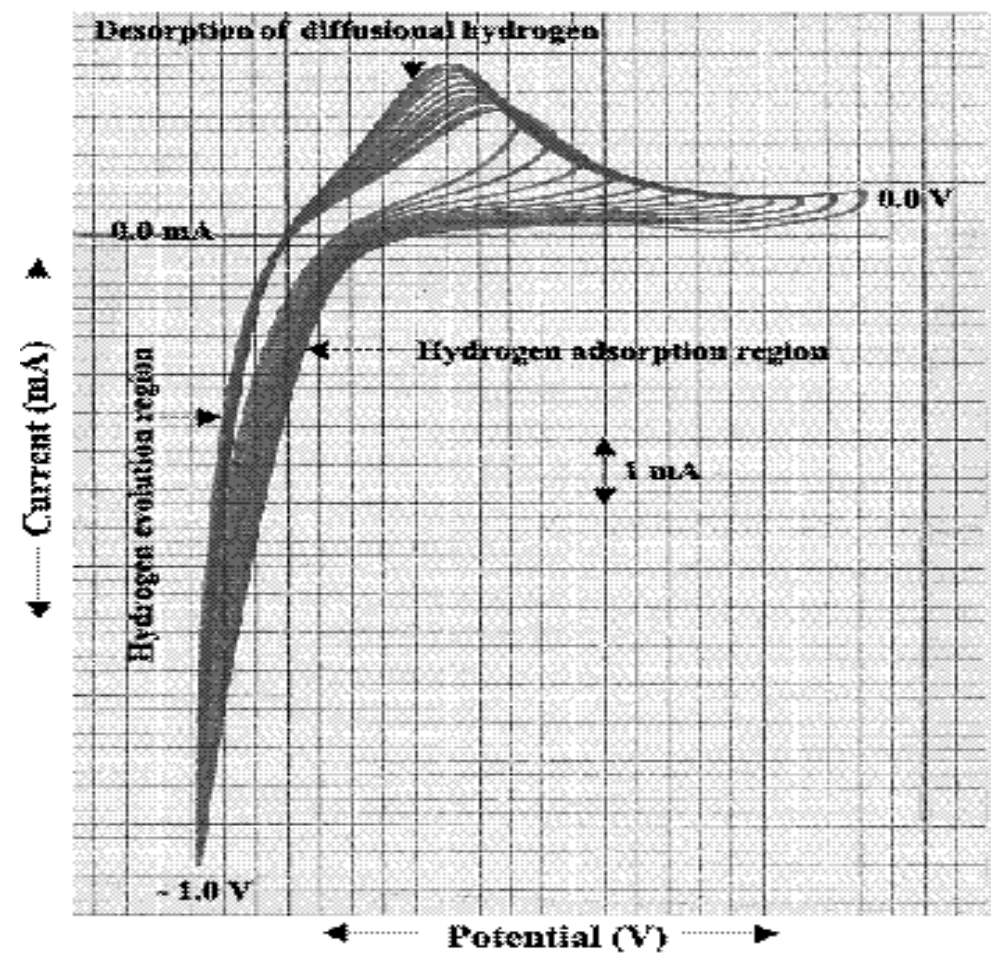

Fig. 7b. Cyclic voltammograms of Pd-20at.\%Ni electrode in 30wt.\%KOH electrolyte in between the potential ranges $-1.0 \mathrm{~V}$ and $+0.0 \mathrm{~V}$ to $-0.55 \mathrm{~V}$.

lattice interstices is smaller than that of Pd. Hydrogen evolution current decreased withfurther decreasing the potential range due to decrease in hydrogen adsorption region. From the above observations, it is possible to understand the mechanism of hydrogen evaluation reaction (HER) over the electrode surface. HER proceeds via three steps involving atomic hydrogen adsorped on the electrode surface namely water reduction with hydrogen adsorption known as Volmer step. To evolve hydrogen, two parallel competitive steps- electrochemical known as Heyrovsky step and chemical known as Tafel step follow the Volmer step. The mechanism can be represent as:

Volmer step: [Pd-Ni] $+\mathrm{H}_{2} \mathrm{O}+\mathrm{e}=[\mathrm{Pd}-$

$\mathrm{Ni}] \mathrm{H}_{\text {ads }}+\mathrm{OH}^{-}$

Heyrovsky step: [Pd-Ni] $\mathrm{H}_{\text {ads }}+\mathrm{H}_{2} \mathrm{O}+\mathrm{e}=$

$$
\mathrm{H}_{2}+[\mathrm{Pd}-\mathrm{Ni}]+\mathrm{OH}^{-}
$$

Tafel step: $2[\mathrm{Pd}-\mathrm{Ni}] \mathrm{H}_{\mathrm{ads}}=2[\mathrm{Pd}-\mathrm{Ni}]+\mathrm{H}_{2}$

\section{Conclusions}

Convinced on the necessity of effective electrode for electrolysis, the efficiency of a Pd20at.\%Ni electrode was investigated in $30 \mathrm{wt} \% \mathrm{KOH}$ electrolyte at room temperature by cyclic voltammetry. Cyclic voltammogram of the electrode showed three couples of redox peaks those were originated 
from the transformation of zero valent metal to their higher oxides in three consecutive steps and vice versa in between the potential range -1.0 to $+0.65 \mathrm{~V}$. A single anodic peak also found in the voltammogram which was appeared due the desorption of absorped hydrogen in the Pd-Ni lattice. The redox reaction kinetics of the electrode surface showed combined behavior of $\mathrm{Pd}$ and $\mathrm{Ni}$ electrodes. Addition of $\mathrm{Ni}$ with $\mathrm{Pd}$, gave fruitful result for the oxygen evolution. The electrode showed equal and 4.2 times higher oxygen evolution current densities than the $\mathrm{Ni}$ and Pd electrodes. The new morphology of the electrode surface formed due to the addition of Ni with Pd delivered this benefit. The electrode showed $100 \%$ better hydrogen evolution efficiency than the $\mathrm{Ni}$ electrode. Almost 70\% hydrogen evolution efficiency of Pd electrode was found at the potential range - 1.0 to $-0.05 \mathrm{~V}$. The electrode could be tested as the cathode and anode of an electrolyzer to generate hydrogen and oxygen for the future purposes.

\section{Acknowledgements}

One of the authors is grateful to the Professor Yoshiichi Sakamoto, Department of Materials Science and Engineering, Nagasaki University, Japan, for supplying him the pure Pd and Pd-20at.\%Ni plates.

\section{Reference}

Aki, H. Yamamoto, S. Kongoh, J. Maeda, T. Yamaguchi, H. Murata and A. Ishii, J. (2006) Fuel cells and energy networks of electricity, heat and hydrogen in residential area. Int. J. Hydrogen Energy 31: 967-980.
Brossard, L. (1991) Electrolysis of 30wt\%KOH solution at $70^{\circ} \mathrm{C}$ on iron electrodes electrocoated with cobalt. Materials Chemistry and Phys. 30 (1) : 61-67.

Brossard, L. and Marquis, B. (1994) Electrocatalytic behavior of $\mathrm{Co} / \mathrm{Cu}$ electrodeposits in $1 \mathrm{M} \mathrm{KOH}$ at $30^{\circ} \mathrm{C}$. Int. J. Hydrogen Energy 19 (3): 231-237.

Chi, B. Lin, H.Li, J. Wang and N. Yang, J. (2006) Comparison of three preparation methods of $\mathrm{NiCO}_{2} \mathrm{O}_{4}$ electrodes. Int. J. Hydrogen Energy 31: 1210-1214.

Choquette, Y. Brossard, L.Laisa, A. and Menard, H. (1990) Investigation of hydrogen evolution on raney-nickel composite-coated electrodes. Electrochemica Acta 35 (8): 1251-1256.

Conway, B.E. Bai, L. and Sattar, M. A. (1987) Role of the transfer coefficient in electrocatalysts: Applications to the $\mathrm{H}_{2}$ and $\mathrm{O}_{2}$ evolution reactions and the characterization of participating adsorbed intermediates. Int. J. Hydrogen Energy 12 (9): 607-621.

Dandapani, B. and Bockris, J.O.M. (1986) Electrochemical recycling of iron for hydrogen production. Int. J. Hydrogen Energy 11(2): 101-105.

Giz, M.J. De. Silva, J.C.P. Da. Ferreira, M. Machado, S. A. S. Ticianelli, E. A. Avaca and L. A. Gonzalez, E. R. (1990) Progress on the development of activated cathodes for water electrolysis. Hydrogen Energy Progress VIII (1): 405-414.

$\mathrm{Hu}$, C.C. and Wu, Y.R. (1993) Bipolar performance of the electroplated Fe-Ni deposits for water electrolysis. Materials Chemistry and Phys. 82 (3): 588-596. 
Huot, J.Y. and Brossard, L. (1987) Time dependence of the hydrogen discharge at $70^{\circ} \mathrm{C}$ on nickel cathodes. Int. J. Hydrogen Energy 12 (12): 821-830.

Jaksic, J.M. Krstajic, N.V. Grgur, B. N. and Jaksic M. M. (1998) Hydridic and electrocatalytic properties of hypo-hyper-delectronic combinations of transition metal intermetallic phases. Int. J. Hydrogen Energy 23(8) 667-681.

Jaksic, M.M. Johansen, B. and Tunold, R. (1993) Electrochemical behavior of Pd in acidic and alkaline solutions of heavy and regular water. Int. J. Hydrogen Energy 18 (2): 111124.

Kaninski, M.P.M. Stojic, D.L. Saponjic, D.P. Potkonjak, N.I. and Miljannic, S. S. (2006) Comparison of different electrode materials: Energy requirements in the electrolytic hydrogen evolution process. J. Power sources 157 (2): 758-764.

Kibria, M. F. Mridha, M. Sh. and Khan, A. H. (1995). Electrochemical studies of a nickel electrode for the hydrogen evolution reaction. Int. J. Hydrogen Energy 20 (6): 435440 .

Kibria, M.F. and Mridha, M. Sh. (1996). Electrochemical studies of the nickel electrode for the oxygen evolution reaction. Int. J. Hydrogen Energy 21 (3): 179-182.

Kibria, A.K.M.F. and Sakamoto, Y. (1997) Hysteresis of pressure-composition and electrical resistance-composition relationships of palladium-hydrogen system. Materials Science and Eng. 49B: 227-232.
Kibria, A.K.M.F. and Tarafdar, S.A. (2002) Electrochemical studies of a nickel-copper electrode for the oxygen evolution reaction (OER). Int. J. Hydrogen Energy 27: 879-884.

Kreuter, W. and Hofman, H. (1998) Electrolysis: The important energy transformer in a world of sustainable energy. Int. $J$. Hydrogen Energy 22 (8): 661-666.

Kreysa, G. and Haklansson, B. (1986) Electrolysis by amorphous metals of hydrogen and oxygen evolution in alkaline solution. $J$. Electroanal. Chem. 201 (1): 61-83.

Lewis, F. A. (1967) The palladium hydrogen system, Academic press, pp. 71.

Podesta, J.J. and Piatti, R.C.V. (1997) Amorphous Pd-P, Au-P, and Co-P alloys as cathode materials in alkaline solution for oxygen reduction. Int. J. Hydrogen Energy 22 (8): 753-758.

Vijh, A.K. and Belanger, A. (1986) Electrocatalysis of the hydrogen evolution reaction by metals and Pd-Ag alloys in relation to their electronic configuration. Int. J. Hydrogen Energy 11 (3): 147-151.

Vracar, L. J. Burojevic, S. and Krstajic, N. (1998) The surface processes at Pd-Ni in acid and alkaline solutions. Int. J. Hydrogen Energy 23 (12): 1157-1164.

Wicke, E. Brodowsky, H. and Zuchner, H. (1978) Hydrogen in Metals II, Springer, New York, pp. 223.

Received : July 08, 2007;

Accepted : October 07, 2007 